Published in final edited form as:

Curr Obes Rep. 2012 March 1; 1(1): 1-8. doi:10.1007/s13679-011-0001-8.

\title{
Gut Microbiota and Obesity
}

\author{
Kyle J. Wolf ${ }^{a}$ and Robin G. Lorenz ${ }^{a, b, 1,2}$ \\ aDepartment of Microbiology at the University of Alabama at Birmingham \\ ${ }^{b}$ Department of Pathology at the University of Alabama at Birmingham
}

\begin{abstract}
The current obesity epidemic clearly has many causes, including the impact of our modern world on both our diet and our lifestyle/physical activity. Although many interventions have been recommended, the prevalence of obesity continues to rise and has forced a re-evaluation of the potential interventions that could have an impact. In recent years it has been definitively shown that microbiota in the gastrointestinal tract are altered in obese individuals. Recent data provide a potential mechanistic understanding of the interactions between microbiota and obesity and allow potential new interventions to the control of obesity to be proposed.
\end{abstract}

\section{Keywords}

Microbiota; Obesity; Gastrointestinal; Inflammation; Energy; Gut

\section{Introduction}

There is currently an epidemic of obesity occurring in the United States, with the most recent study showing a prevalence of $32.2 \%$ among adult men and $35.5 \%$ among adult women [1]. Significant factors in this epidemic are our diets, which are increasingly high in carbohydrates and fats, and our lack of physical activity [2]. Although critical, these factors clearly are not the whole story; in 2004, Bäckhed et al. [3] proposed an additional mechanism that implicated gastrointestinal (GI) microbiota.

The resident population of microbiota is an essential part of the development and maturity of the host intestinal track and immune system and has therefore come to be considered by some a virtual organ known as the microbiome [4]. The gut microbiome is the totality of microbes (bacteria, viruses, etc.), their genetic elements (genomes), and environmental interactions within the GI track. This microbiome contains over 10 times more organisms than the number of cells in a human body, but unlike other organs its composition is somewhat unstable. The resident populations of bacteria can be altered within 24 hours of a dietary change; therefore, obtaining a unified picture of the microbiome can be a challenging proposition [5].

The involvement of the gut microbiota in the obesity epidemic was first suggested by the fact that adult germ-free (GF) (ie, bacteria-free) C57BL/6 mice had a $60 \%$ increase in body

\footnotetext{
${ }^{2}$ Corresponding author: Robin G. Lorenz, Department of Pathology, University of Alabama at Birmingham, 1825 University Boulevard, SHEL 602, Birmingham, AL 35294-2182, USA. rlorenz@uab.edu.

${ }^{1}$ Contact information for Kyle J. Wolf: Department of Microbiology, University of Alabama at Birmingham, 1825 University Boulevard, SHEL 671, Birmingham, AL 35294-2182, USA. kwolf@uab.edu
}

Disclosure

No potential conflicts of interest relevant to this article were reported. 
fat content when they were conventionalized (ie, colonized) with cecal microbiota from a healthy, normal C57BL/6 mouse [3]. The mechanism for this increase in body fat content was hypothesized to include the fact that the microbiota would have the ability to regulate energy harvest from food components and therefore alter energy storage in the host. Since that original publication in 2004, there have now been 138 primary data publications and 60 reviews that are found by a PubMed search for obesity and microbiota. These publications have led to the proposal of three unique mechanisms through which microbiota may impact host obesity, and these are discussed in this review.

\section{Experimental Approaches to the Study of the Microbiome}

The study of the gut microbiome is unique among organ systems, as the microbiome can be shed and replenished and there is the unique opportunity to study this "organ" over long periods of time by obtaining fecal samples from a single individual. This type of analysis has led to the concept of "enterotypes" of the gut microbiome and recent data from 22 individuals have indicated a limited number of host-microbial symbiotic states that might respond differently to diets [6]. However, data from fecal samples have to be interpreted with caution, as several groups have indicated that fecal microbiota communities differ from mucosal-associated bacteria in the GI tract [7, 8]. As the techniques to study, measure, and modify the microbiome are somewhat unique to the field and sometimes are not within the usual repertoire of skills other biologists would utilize, we have detailed some experimental approaches in this review.

\section{Bacterial Culture and Identification}

Bacterial culture and identification have been extensively used to identify pathogenic or residential bacterial components of feces or tissue [9]. This method utilizes long-standing phenotypic identification practices such as motility, shape, colony structure, and sugar/ metabolite utilization. However, many species remain undefined because there currently is no known method to culture these groups outside of the intestinal tract, and for this reason more advanced methods have been developed using nucleotide amplification.

\section{Fluorescence In Situ Hybridization}

Fluorescence in situ hybridization (microscopy-FISH) has historically been utilized to identify bacteria present in tissue sections without nucleic acid purification. Briefly, radioactive or fluorescent-tagged nucleic acid-based probes targeting $16 \mathrm{~S}$ ribosomal RNA are used to permeate preserved histologic samples and allow for visualization of specific organisms [10]. This procedure has the advantage of precise localization of the bacteria, but does not give quantitative results. A newer method that combines FISH with flow-cytometry (FCM-FISH) no longer allows for tissue localization, but when combined with DNA stains is a rapid, reliable, and quantitative method for the analysis of mixed bacterial samples in feces [11].

\section{Quantitative Real-Time Polymerase Chain Reaction}

Quantitative real-time polymerase chain reaction (qRT-PCR) is a second method for enumerating the numbers of bacteria present in feces (or tissue samples), but it relies on nucleic acid extraction from the samples. qRT-PCR has very high sensitivity and reproducibility and is very rapid to perform [12]. As with FISH, specific microorganisms are detected based on sequence-specific probes, but only organisms with known sequences can be quantified. 


\section{Denaturing Gradient Gel Electrophoresis and 454 Pyrosequencing}

There are two nucleic acid-based methods that can identify unknown and nonculturable organisms. Denaturing gradient gel electrophoresis (DGGE) is a method of creating a physical picture of bacterial diversity through a two-dimensional (2D) denaturing gel. DNA is amplified and separated on the 2D gel, where the amplified products migrate according to G:C content and are visualized as unique bands on the gel [13]. Bacteria can be identified through a combination of purification of DNA from the gel and Sanger sequencing methods [14]. Although Sanger sequencing methods can be used to identify numerous bacterial sequences in GI samples, the new high-throughput pyrosequencing technology offers a more rapid and cost-effective method for total microbiome analysis. 454 Pyrosequencing is a method that differs from traditional sequencing in that it does not measure chain termination, but instead relies on the detection of pyrophosphate release upon nucleotide incorporation. This method has now been combined with a novel barcoding approach, which allows simultaneous sequencing of multiple individual samples $[15,16]$.

\section{Metatranscriptomic Approach and Nuclear Magnetic Resonance}

The use of these rapid and extensive sequencing techniques has revealed the enormous diversity of the GI microbiota and its rapidly changing nature [5, 17]. Therefore, recent studies have combined these methods with bacterial gene expression analysis. This metatranscriptomic approach has identified a "core microbiome" at the gene expression, rather than at the organismal lineage, that is associated with obesity [17, 18]. A second method to look at the function of this "core microbiome" is via metabolomics. Nuclear magnetic resonance (NMR) can be used to measure very small molecules, such as individual amino acids, carbohydrates, and lipids/fatty acids. By utilizing the unique magnetic properties from each molecule, NMR measures the magnetic radiation from a sample and is able to measure hundreds of molecules. This is optimal when attempting to measure small molecules from either serum or even feces [19]. Using this type of technique, microbial metabolites generated during colonic fermentation of food stuffs can be determined and their subsequent impact on blood and tissue metabolites determined [20-22].

\section{Germ-Free Models}

The concept of altering commensal populations to enhance the health of humans has been long studied, but has only recently been utilized for manipulation of the obese phenotype. Through the use of mouse models, we are able to extract information about how each individual group of bacteria contributes to the microbiome and to the host. GF models are mice or rats that are completely bacteria free. These mice are optimal as negative controls and also invaluable as a "clean source" when looking to mono-colonize an individual with single bacteria to understand how they impact the host [23-25]. One of the landmark experiments indicating the role of the microbiota in obesity utilized GF mice, which were colonized with an "obese microbiota" or a "lean microbiota." The "obese microbiota" transfer resulted in mice with a greater increase in total body fat and clearly identified the gut microbiota as a contributing factor in the obesity story [26]. Mice that are colonized with a specific known bacteria are termed gnotobiotic (or "known life") and can help us understand the role of specific bacteria in inflammation and disease course [24].

\section{Mechanisms Linking Microbiota and Obesity}

The earliest observations indicated that mouse models of obesity (ie, the $o b / o b$ mouse) had an alteration in the overall proportions of two major divisions of bacteria. Normal humans and mice have $60 \%$ to $80 \%$ Firmicutes (which are primarily nonculturable, butyrateproducing Clostridium cluster XIVa) and 20\% Bacteroidetes (Cytophaga-FlavobacteriumBacteroides) [27]. However, the obese mouse model $(o b / o b)$ had a $50 \%$ reduction in 
Bacteroidetes and an increase in Firmicutes [27, 28]. A similar decrease in Bacteroidetes and increase in Firmicutes is also seen when C57BL/6 mice are fed a high-fat (HF) diet [28, 29, $30 \bullet, 31,32 \bullet$. The reciprocal result is seen in caloric reduction studies [30•]. To determine if these alterations in microbiota contributed to HF diet-induced obesity and insulin resistance, several groups have now fed a HF diet to GF mice. Two groups used GF C57BL/6 mice and both determined that GF animals were protected against both obesity and insulin resistance after HF diet, therefore implying that gut microbiota clearly influence the effects of diet on the host [33, 34]. However, a third group utilized $\mathrm{C} 3 \mathrm{H}$ mice and concluded that the absence of intestinal microbiota did not protect mice from diet-induced obesity [35]. Although the reasons for this difference in results are not known, one possibility is that some strains of $\mathrm{C} 3 \mathrm{H}$ mice are resistant to the gram-negative bacterial product, lipopolysaccharide (LPS). As increased levels of and response to systemic LPS have been proposed as one of the potential mechanisms of microbiota-influenced obesity (see below), if these mice cannot respond to LPS, then this might explain the discrepancy.

\section{Altered Energy Intake}

The resident bacteria within the GI tract are responsible for a significant portion of our energy intake, allowing us access to energy sources that may have otherwise been indigestible. The Firmicutes that are increased in obese mice and humans have been shown to be more adept at breaking down otherwise indigestible carbohydrates and converting them into absorbable energy products [5, 17, 36, 37]. If the microbiota were to shift between lean and obese individuals, it would seem likely that this change would affect the efficiency of energy production/absorption in the GI tract and may either facilitate or inhibit progression toward obesity. When analyzed via gene chips, it was observed that bacteria from obese individuals have increased expression in gene sets specific to motility, transcription, and saccharide metabolism [26].

Taking all of this into account, you can begin to piece together a picture of the path toward obesity. Westernized diets push the commensal populations toward a Firmicutes-friendly environment, ending with an overall increase in Clostridia populations. The increased Clostridia populations, acting as more efficient carbohydrate metabolizers, extract greater energy from the caloric intake, allowing for higher energy utilization. That extra energy, if not spent, will ultimately be stored as fat deposits. To better understand the disposition obese individuals have toward increased energy consumption, colonic/cecal health was examined as well as GI metabolites. Upon examination, cecal contents of both mouse and human studies revealed that obese individuals had significantly increased levels of shortchain fatty acids (SCFAs) [36, 38]. SCFAs such as acetate, propionate, and butyrate were in greater abundance in obese individuals. SCFAs are common byproducts of carbohydrate metabolism [39]. It should not be surprising that most SCFAs (specifically butyrate) producing bacteria belong to Clostridia cluster XIVa and IV [40]. Concentrations of SCFAs were measured in lean and obese mice via NMR. Overall, SCFAs were increased in the urine of obese mice compared with lean [41]. Although acetate has been primarily researched as a factor in high cholesterol, butyrate is highly regarded as an integral component to colonic health $[42,43]$.

\section{Increased Fatty Acid Metabolism}

One of the first publications that implicated the gut microbiota as an environmental factor that regulated fat storage observed that GF C57BL/6 mice conventionalized with normal microbiota had a suppressed expression of intestinal fasting-induced adipose factor/ angiopoietin-like protein 4 (Fiaf/Angpt14) [3]. Fiaf/Angptl4 is a target of the nuclear receptor PPAR- $a$ in the liver, but is also expressed in white adipose tissue, skeletal muscle, and intestine [44]. One function of Fiaf/Angptl4 appears to be its ability to raise plasma 
triglycerides via its ability to inhibit lipoprotein lipase activity. Through the use of Fiaf knockout mice it was established that the suppression of Fiaf/Angptl4 is essential for the microbiota-induced deposition of triglycerides in adipocytes seen after conventionalization of GF mice [3, 33]. It has also recently been shown that the Chinese supplement Rhizoma coptidis can lower body adipose weight and that one potential mechanism for this finding is an inhibition of gut bacterial growth and a subsequent increase in Fiaf/Angptl4 expression in the intestine [45].

\section{Microbiota-Associated Inflammation}

For more than 15 years, it has been clear that adipose tissue in obese models has an elevated expression of proinflammatory cytokines such as tumor necrosis factor-a (TNF-a). This has been reported for multiple rodent models of obesity, including the diabetes $(d b / d b)$, obese $(o b / o b)$, and tubby $(t u b / t u b)$ mice and the Zucker ( $f a / f a)$ rat, as well as obese female patients $[46,47]$. This TNF-a is primarily made by adipose tissue macrophages and it mediates insulin resistance through its ability to decrease the tyrosine kinase activity of the insulin receptor [48, 49]. Diets known to induce obesity and insulin resistance, such as the HF diet, can increase expression of TNF-a [50]. However, the induction of obesity and insulin resistance are ameliorated if mice are deficient in either TNF- $a$ or the TNF- $a$ R $[51,52]$.

But why does a HF diet and/or obesity lead to a chronic inflammatory state? Initially, the hypothesis was that increased nutritional fatty acids could lead to activation of the toll-like receptors (specifically TLR4) and subsequent inflammation [53]. However, as discussed above, a HF diet shifts the intestinal microbiome very quickly to a decrease in Bacteroidetes and an increase in both Firmicutes and Proteobacteria [5, 29]. One proposal is that this alteration in intestinal microbiota could lead to increased activation of TLR4, and therefore be partially responsible for the chronic inflammatory state seen in obese individuals.

To address this question, Cani et al. [54] initially asked if a HF diet would increase plasma concentrations of LPS, a TLR4 ligand made by gram-negative bacteria. This low level of LPS in the plasma has been termed "metabolic endotoxemia." The data indicated that a HF diet in C57BL/6 mice did increase levels of plasma LPS and that direct infusion of LPS mimicked the physiologic effects of a HF diet [54]. Moreover, the effects of the HF diet were ameliorated in mice lacking a component of the TLR4 receptor complex-CD14. This same group went on to implicate intestinal bacteria in the increased plasma concentrations of LPS through the use of oral broad-spectrum antibiotics, which significantly decreased the levels of intestinal microbiota and the levels of plasma LPS [55]. Additionally, the administration of a prebiotic (oligofructose) resulted in an increase in gram-positive intestinal bacteria (including Bificobacteria) and a decrease in plasma LPS [56].

These observations allow the consideration that plasma LPS might be a biomarker of the status of obesity-prone individuals or the impact of therapeutic probiotics on obesityassociated intestinal microbiota. Several recent studies indicate that the answer may be yes. The first study investigated serum LPS activity in more than 7000 subjects with a 10-year follow-up. This study concluded that both previously diagnosed diabetic patients, as well as patients with newly diagnosed diabetes (incident diabetes) had higher LPS levels than nondiabetes individuals [57]. In addition, therapeutics such as oral probiotics (Lactobacillus case1), when given to mice with diet-induced obesity, can improve not only insulin resistance, but can also reduce plasma levels of LPS-binding protein (a marker of endotoxemia) [58].

This involvement of TLR activation was confirmed in a Sprague-Dawley rat model fed a HF diet, which can exhibit either an obesity-prone or an obesity-resistant phenotype. All the obesity-prone rats, but none of the obesity-resistant rats, had increased TLR4 activation [37]. 
Additional support comes from an experiment utilizing gnotobiotic and conventional Swiss Webster mice, which demonstrated that conventionally raised mice on the HF diet had increased hepatic levels of the inflammatory marker serum amyloid A, but that this effect of the HF diet was ameliorated in MyD88-deficient mice (MyD88 is a component of the TLR signaling pathway) [59]. Although TLR4 has been the receptor most implicated in this mechanism, it has also been recently shown that mice lacking TLR5 have metabolic syndrome [60]. This is at least in part due to an altered intestinal microbiota, as transfer of the microbiota from a TLR5-deficient mouse to a wild-type gnotobiotic mouse conferred metabolic syndrome to the recipients [60]. Intriguingly, a recent study on insects has also demonstrated a metabolic syndrome that is induced by a protozoan intestinal infection [61].

The mechanism for this increased plasma LPS from intestinal microbiota is probably increased intestinal permeability. C57BL/6 mice fed a HF diet have increased permeability to small molecules, such as FITC-dextran and also have decreased or altered expression of the tight junctional proteins occludin and zonulin-1 [55]. Similar findings were seen in HF diet-raised obesity-prone Sprague-Dawley rats, but not in obesity-resistant rats [37]. The impact of intestinal microbiota on permeability has recently been shown to involve glucagon-like peptide-2 (GLP-2) [62]. If $o b / o b$ mice are given a GLP-2 agonist, then intestinal permeability is lowered, and tight-junction integrity and the systemic inflammatory phenotype is improved. As GLP-2 has receptors not only in the intestine but also in the brain, it is an intriguing possibility that there is a gut-brain axis that might potentially link intestinal microbiota to feeding behaviors [63]. Intracerebroventricular infusion of GLP-2 can inhibit food intake and, consequently, alterations in intestinal microbiota may have long-term effects on the gut-brain axis and body weight homeostasis [64].

\section{Establishment of the Microbiome}

It appears clear that the microbiota can impact energy metabolism and be associated with obesity and metabolic endotoxemia. If so, then the questions arise of: How do we acquire our microbiota? What is known to influence the microbiota present? Can we modify our microbiota in a predetermined fashion? Many studies have shown that the initial bacterial colonization of the intestine is at birth, primarily from the mother and/or other caregivers $[65,66]$. However, newer work has now focused on the impact of microbiota on weight gain during pregnancy and on whether this impacts the subsequent weight of the child later in life.

The majority of this work has been published by a group from Finland, who have primarily utilized the techniques of FCM-FISH and qRT-PCR to show that if a mother was overweight before pregnancy, then she had significant increases in the numbers of fecal Bacteroides-Prevotella group (FCM-FISH) and Staphylococcus aureus (qRT-PCR) from the first to the third trimester [67]. The impact of this alteration in maternal microbiota on the microbiota of 1- and 6-month-old infant stool samples indicated that the infant fecal microbial composition was influenced by the maternal weight gain during pregnancy and by maternal body mass index (BMI) during early pregnancy [68]. Six-month-old infants from mothers with a BMI greater than $25 \mathrm{~kg} / \mathrm{m}^{2}$ had more fecal Clostridium histolyticum (FCMFISH) and Clostridium leptum (qRT-PCR), but less Bifidobacterium genus (qPCR). However, in contrast to the findings in the mothers, the levels of Bacteroides-Prevotella decreased in 6-month old infants from mothers with high BMI or who had excessive weight gain. In support of this decrease in Bacteroides-Prevotella in offspring of overweight mothers, the offspring of rats fed a HF diet also had fewer Bacteroides-Prevotella in the jejunum [69]. Additionally, rats that were exposed to pre-weaning overnutrition also had lower numbers of Bacteroides-Prevotella [70]. 
To determine if this altered microbiotal composition actually has any correlation with weight in children, this same group of children was followed until age 7 years [71]. None of the bacterial groups found to be significant in overweight mothers or their offspring were correlated with increased weight gain in childhood; however, increased levels of $S$. aureus during infancy did correlate with a child being overweight at age 7 years. A second study also investigated whether factors known to alter intestinal microbiota have an effect on body weight at age 7 years [72]. Factors investigated included delivery mode, maternal prepregnancy BMI, and early exposure to antibiotics ( $<6$ months of age). Children from mothers with a high pre-pregnancy BMI were more likely to have overweight children at age 7 years; however, this study did not correlate these findings with the intestinal microbiota composition.

Although these studies appear to indicate that our microbiota is established very early in life, there are also studies that indicate that microbiota can be manipulated by various weight loss techniques. In adolescents subjected to an obesity treatment program including both calorie restriction and increased physical activity, there was an increase in the BacteroidesPrevotella group and a decrease in Clostridium spp [73, 74]. In adults who have undergone Roux-en-Y gastric bypass the Bacteroides-Prevotella and Escherichia coli species increased 3 months after surgery, whereas lactic acid bacteria (including Lactobacillus/Leuconostoc/ Pedicoccus group and Bifidobacterium genus) decreased [5, 76].

If weight loss is associated with altered microbiota and if the obesity phenotype can be transferred by fecal microbiota, then it could be proposed that a bacteria might exist that could induce a lean phenotype. This concept has been most extensively tested through the administration of probiotics. Probiotics are live microorganisms that are thought to be beneficial to the host. The most common types are lactic acid bacteria and bifidobacteria and are often found in yogurt or dietary supplements. Studies using Lactobacillus rhamnosus GG, Lactobacillus plantarum strain 14, Lactobacillus paracasei ssp paracasei F19, and Bifidobacterium breve B-3 all demonstrated that probiotic intervention appears to have a beneficial effect on obesity [77-80]. The probiotics appear to work by reducing mean adipocyte size, inhibiting lipoprotein lipase, and improving insulin sensitivity [77-79].

\section{Conclusions}

Obese individuals and models all show a propensity for a dysbiosis that includes an increased ratio of Firmicutes:Bacteroidetes. This alteration in the proportion of bacteria in the lumen of the GI track affects not only the ability of the microbiome to generate energy sources from indigestible carbohydrates, but also the deposition of triglycerides in adipocytes. This altered bacteria also appears to have an increased exposure to the host immune system due to a leaky intestinal barrier and induces a constant state of chronic inflammation. This impact of the microbiota on obesity has led to multiple preliminary studies on the use of "good" probiotic bacteria to alter the obese phenotype. These studies have all shown that probiotic intervention has a beneficial effect and may lead to novel interventions for overweight or obese human patients.

\section{References}

Papers of particular interest, published recently, have been highlighted as:

- Of importance

•• Of major importance 
1. Flegal KM, Carroll MD, Ogden CL, Curtin LR. Prevalence and trends in obesity among US adults, 1999-2008. JAMA : the journal of the American Medical Association. 2010; 303(3):235-241. [PubMed: 20071471]

2. James WP. The fundamental drivers of the obesity epidemic. Obes Rev. 2008; 9(Suppl 1):6-13. [PubMed: 18307693]

3. Bäckhed F, Ding H, Wang T, Hooper LV, Koh GY, Nagy A, et al. The gut microbiota as an environmental factor that regulates fat storage. Proceedings of the National Academy of Sciences of the United States of America. 2004; 101(44):15718-15723. PMCID: 524219. [PubMed: 15505215]

4. Shanahan F. The host-microbe interface within the gut. Best practice \& research Clinical gastroenterology. 2002; 16(6):915-931. [PubMed: 12473298]

5. Turnbaugh PJ, Ridaura VK, Faith JJ, Rey FE, Knight R, Gordon JI. The effect of diet on the human gut microbiome: a metagenomic analysis in humanized gnotobiotic mice. Sci Transl Med. 2009; 1(6):6ra14. PMCID: 2894525.

6. Arumugam M, Raes J, Pelletier E, Le Paslier D, Yamada T, Mende DR, et al. Enterotypes of the human gut microbiome. Nature. 2011; 473(7346):174-180. [PubMed: 21508958]

7. Zoetendal EG, von Wright A, Vilpponen-Salmela T, Ben-Amor K, Akkermans AD, de Vos WM. Mucosa-associated bacteria in the human gastrointestinal tract are uniformly distributed along the colon and differ from the community recovered from feces. Applied and environmental microbiology. 2002; 68(7):3401-3407. PMCID: 126800. [PubMed: 12089021]

8. Marteau P, Pochart P, Dore J, Bera-Maillet C, Bernalier A, Corthier G. Comparative study of bacterial groups within the human cecal and fecal microbiota. Applied and environmental microbiology. 2001; 67(10):4939-4942. PMCID: 93255. [PubMed: 11571208]

9. Versalovic, J. Manual of clinical microbiology. 10th. Washington, DC: ASM Press; 2011. American Society for Microbiology.

10. Zoetendal EG, Collier CT, Koike S, Mackie RI, Gaskins HR. Molecular ecological analysis of the gastrointestinal microbiota: a review. The Journal of nutrition. 2004; 134(2):465-472. [PubMed: 14747690]

11. Vaahtovuo J, Korkeamaki M, Munukka E, Viljanen MK, Toivanen P. Quantification of bacteria in human feces using 16S rRNA-hybridization, DNA-staining and flow cytometry. Journal of microbiological methods. 2005; 63(3):276-286. [PubMed: 15935498]

12. Zhang T, Fang HH. Applications of real-time polymerase chain reaction for quantification of microorganisms in environmental samples. Appl Microbiol Biotechnol. 2006; 70(3):281-289. [PubMed: 16470363]

13. Satokari RM, Vaughan EE, Smidt H, Saarela M, Matto J, de Vos WM. Molecular approaches for the detection and identification of bifidobacteria and lactobacilli in the human gastrointestinal tract. Systematic and applied microbiology. 2003; 26(4):572-584. [PubMed: 14666986]

14. Schmitz JM, Durham CG, Schoeb TR, Soltau TD, Wolf KJ, Tanner SM, et al. Helicobacter felisAssociated Gastric Disease in Microbiota-Restricted Mice. The journal of histochemistry and cytochemistry : official journal of the Histochemistry Society. 2011; 59(9):826-841. [PubMed: 21852692]

15. Parameswaran P, Jalili R, Tao L, Shokralla S, Gharizadeh B, Ronaghi M, et al. A pyrosequencingtailored nucleotide barcode design unveils opportunities for large-scale sample multiplexing. Nucleic Acids Res. 2007; 35(19):e130. PMCID: 2095802. [PubMed: 17932070]

16. Armougom F, Raoult D. Use of pyrosequencing and DNA barcodes to monitor variations in Firmicutes and Bacteroidetes communities in the gut microbiota of obese humans. BMC Genomics. 2008; 9:576. PMCID: 2625370. [PubMed: 19046425]

17. Turnbaugh PJ, Hamady M, Yatsunenko T, Cantarel BL, Duncan A, Ley RE, et al. A core gut microbiome in obese and lean twins. Nature. 2009; 457(7228):480-484. PMCID: 2677729. [PubMed: 19043404]

18. Gosalbes MJ, Durban A, Pignatelli M, Abellan JJ, Jimenez-Hernandez N, Perez-Cobas AE, et al. Metatranscriptomic approach to analyze the functional human gut microbiota. PLoS One. 2011; 6(3):e17447. PMCID: 3050895. [PubMed: 21408168]

19. Romick-Rosendale LE, Goodpaster AM, Hanwright PJ, Patel NB, Wheeler ET, Chona DL, et al. NMR-based metabonomics analysis of mouse urine and fecal extracts following oral treatment 
with the broad-spectrum antibiotic enrofloxacin (Baytril). Magn Reson Chem. 2009; 47(Suppl 1):S36-S46. [PubMed: 19768747]

20. Jacobs DM, Gaudier E, van Duynhoven J, Vaughan EE. Non-digestible food ingredients, colonic microbiota and the impact on gut health and immunity: a role for metabolomics. Current drug metabolism. 2009; 10(1):41-54. [PubMed: 19149512]

21. Wikoff WR, Anfora AT, Liu J, Schultz PG, Lesley SA, Peters EC, et al. Metabolomics analysis reveals large effects of gut microflora on mammalian blood metabolites. Proceedings of the National Academy of Sciences of the United States of America. 2009; 106(10):3698-3703. PMCID: 2656143. [PubMed: 19234110]

22. Calvani R, Miccheli A, Capuani G, Tomassini Miccheli A, Puccetti C, Delfini M, et al. Gut microbiome-derived metabolites characterize a peculiar obese urinary metabotype. Int J Obes (Lond). 2010; 34(6):1095-1098. [PubMed: 20212498]

23. Thompson GR, Trexler PC. Gastrointestinal structure and function in germ-free or gnotobiotic animals. Gut. 1971; 12(3):230-235. PMCID: PMC1411593. [PubMed: 4928173]

24. Wostmann, BS. Germfree and gnotobiotic animal models: background and applications. Boca Raton: CRC Press; 1996.

25. McCracken V, Lorenz R. The gastrointestinal ecosystem: a precarious alliance among epithelium, immunity and microbiota. Cell Microbiol. 2001; 3(1):1-11. [PubMed: 11207615]

26. Turnbaugh PJ, Ley RE, Mahowald MA, Magrini V, Mardis ER, Gordon JI. An obesity-associated gut microbiome with increased capacity for energy harvest. Nature. 2006; 444(7122):1027-1031. [PubMed: 17183312]

27. Ley RE, Backhed F, Turnbaugh P, Lozupone CA, Knight RD, Gordon JI. Obesity alters gut microbial ecology. Proceedings of the National Academy of Sciences of the United States of America. 2005; 102(31):11070-11075. PMCID: 1176910. [PubMed: 16033867]

28. Murphy EF, Cotter PD, Healy S, Marques TM, O'Sullivan O, Fouhy F, et al. Composition and energy harvesting capacity of the gut microbiota: relationship to diet, obesity and time in mouse models. Gut. 2010; 59(12):1635-1642. [PubMed: 20926643]

29. Hildebrandt MA, Hoffmann C, Sherrill-Mix SA, Keilbaugh SA, Hamady M, Chen YY, et al. Highfat diet determines the composition of the murine gut microbiome independently of obesity. Gastroenterology. 2009; 137(5):1716-1724. e1-2. PMCID: 2770164. [PubMed: 19706296]

30. Jumpertz R, Le DS, Turnbaugh PJ, Trinidad C, Bogardus C, Gordon JI, et al. Energy-balance studies reveal associations between gut microbes, caloric load, and nutrient absorption in humans. The American journal of clinical nutrition. 2011; 94(1):58-65. PMCID: 3127503. [PubMed: 21543530] This paper highlights the changes in bacteria over time on different diets between obese and lean individuals. It also emphasizes the importance of microbial makeup on the caloric absorption and colonic health and their links to obesity

31. Turnbaugh PJ, Backhed F, Fulton L, Gordon JI. Diet-induced obesity is linked to marked but reversible alterations in the mouse distal gut microbiome. Cell Host Microbe. 2008; 3(4):213-223. [PubMed: 18407065]

32. Turnbaugh PJ, Gordon JI. The core gut microbiome, energy balance and obesity. J Physiol. 2009; 587(Pt 17):4153-4158. PMCID: 2754355. [PubMed: 19491241] This article correlates the changes in microbiota between obese and lean individuals with the ability to absorb and produce energy by the host and microbial community, respectively. This group has been instrumental in spearheading the research into obesity and commensal bacterial populations.

33. Backhed F, Manchester JK, Semenkovich CF, Gordon JI. Mechanisms underlying the resistance to diet-induced obesity in germ-free mice. Proceedings of the National Academy of Sciences of the United States of America. 2007; 104(3):979-984. PMCID: 1764762. [PubMed: 17210919]

34. Rabot S, Membrez M, Bruneau A, Gerard P, Harach T, Moser M, et al. Germ-free C57BL/6J mice are resistant to high-fat-diet-induced insulin resistance and have altered cholesterol metabolism. The FASEB journal : official publication of the Federation of American Societies for Experimental Biology. 2010; 24(12):4948-4959.

35. Fleissner CK, Huebel N, Abd El-Bary MM, Loh G, Klaus S, Blaut M. Absence of intestinal microbiota does not protect mice from diet-induced obesity. The British journal of nutrition. 2010; 104(6):919-929. [PubMed: 20441670] 
36. Brinkworth GD, Noakes M, Clifton PM, Bird AR. Comparative effects of very low-carbohydrate, high-fat and high-carbohydrate, low-fat weight-loss diets on bowel habit and faecal short-chain fatty acids and bacterial populations. The British journal of nutrition. 2009; 101(10):1493-1502. [PubMed: 19224658]

37. de La Serre CB, Ellis CL, Lee J, Hartman AL, Rutledge JC, Raybould HE. Propensity to high-fat diet-induced obesity in rats is associated with changes in the gut microbiota and gut inflammation. American journal of physiology Gastrointestinal and liver physiology. 2010; 299(2):G440-G448. PMCID: 2928532. [PubMed: 20508158]

38. Schwiertz A, Taras D, Schafer K, Beijer S, Bos NA, Donus C, et al. Microbiota and SCFA in lean and overweight healthy subjects. Obesity (Silver Spring). 2010; 18(1):190-195. [PubMed: 19498350]

39. Flint HJ, Bayer EA, Rincon MT, Lamed R, White BA. Polysaccharide utilization by gut bacteria: potential for new insights from genomic analysis. Nature reviews Microbiology. 2008; 6(2):121131.

40. Louis P, Young P, Holtrop G, Flint HJ. Diversity of human colonic butyrate-producing bacteria revealed by analysis of the butyryl-CoA:acetate CoA-transferase gene. Environmental microbiology. 2010; 12(2):304-314. [PubMed: 19807780]

41. Waldram A, Holmes E, Wang Y, Rantalainen M, Wilson ID, Tuohy KM, et al. Top-down systems biology modeling of host metabotype-microbiome associations in obese rodents. J Proteome Res. 2009; 8(5):2361-2375. [PubMed: 19275195]

42. Macfarlane S, Macfarlane GT. Regulation of short-chain fatty acid production. Proc Nutr Soc. 2003; 62(1):67-72. [PubMed: 12740060]

43. Louis P, Scott KP, Duncan SH, Flint HJ. Understanding the effects of diet on bacterial metabolism in the large intestine. Journal of applied microbiology. 2007; 102(5):1197-1208. [PubMed: 17448155]

44. Kersten S. Regulation of lipid metabolism via angiopoietin-like proteins. Biochem Soc Trans. 2005; 33(Pt 5):1059-1062. [PubMed: 16246045]

45. Xie W, Gu D, Li J, Cui K, Zhang Y. Effects and Action Mechanisms of Berberine and Rhizoma coptidis on Gut Microbes and Obesity in High-Fat Diet-Fed C57BL/6J Mice. PLoS One. 2011; 6(9):e24520. [PubMed: 21915347]

46. Hotamisligil GS, Shargill NS, Spiegelman BM. Adipose expression of tumor necrosis factor-alpha: direct role in obesity-linked insulin resistance. Science. 1993; 259(5091):87-91. [PubMed: 7678183]

47. Catalan V, Gomez-Ambrosi J, Ramirez B, Rotellar F, Pastor C, Silva C, et al. Proinflammatory cytokines in obesity: impact of type 2 diabetes mellitus and gastric bypass. Obes Surg. 2007; 17(11):1464-1474. [PubMed: 18219773]

48. Hotamisligil GS, Peraldi P, Budavari A, Ellis R, White MF, Spiegelman BM. IRS-1-mediated inhibition of insulin receptor tyrosine kinase activity in TNF-alpha- and obesity-induced insulin resistance. Science. 1996; 271(5249):665-668. [PubMed: 8571133]

49. Weisberg SP, McCann D, Desai M, Rosenbaum M, Leibel RL, Ferrante AW Jr. Obesity is associated with macrophage accumulation in adipose tissue. The Journal of clinical investigation. 2003; 112(12):1796-1808. PMCID: 296995. [PubMed: 14679176]

50. Borst SE, Conover CF. High-fat diet induces increased tissue expression of TNF-alpha. Life Sci. 2005; 77(17):2156-2165. [PubMed: 15935403]

51. Yamato M, Shiba T, Ide T, Seri N, Kudo W, Ando M, et al. High-fat diet-induced obesity and insulin resistance were ameliorated via enhanced fecal bile acid excretion in tumor necrosis factoralpha receptor knockout mice. Mol Cell Biochem. 2011

52. Bouter B, Geary N, Langhans W, Asarian L. Diet-genotype interactions in the early development of obesity and insulin resistance in mice with a genetic deficiency in tumor necrosis factor-alpha. Metabolism. 2010; 59(7):1065-1073. [PubMed: 20045154]

53. Fessler MB, Rudel LL, Brown JM. Toll-like receptor signaling links dietary fatty acids to the metabolic syndrome. Curr Opin Lipidol. 2009; 20(5):379-385. PMCID: 3099529. [PubMed: 19625959] 
54. Cani PD, Amar J, Iglesias MA, Poggi M, Knauf C, Bastelica D, et al. Metabolic endotoxemia initiates obesity and insulin resistance. Diabetes. 2007; 56(7):1761-1772. [PubMed: 17456850]

55. Cani PD, Bibiloni R, Knauf C, Waget A, Neyrinck AM, Delzenne NM, et al. Changes in gut microbiota control metabolic endotoxemia-induced inflammation in high-fat diet-induced obesity and diabetes in mice. Diabetes. 2008; 57(6):1470-1481. [PubMed: 18305141]

56. Cani PD, Neyrinck AM, Fava F, Knauf C, Burcelin RG, Tuohy KM, et al. Selective increases of bifidobacteria in gut microflora improve high-fat-diet-induced diabetes in mice through a mechanism associated with endotoxaemia. Diabetologia. 2007; 50(11):2374-2383. [PubMed: 17823788]

57. Pussinen PJ, Havulinna AS, Lehto M, Sundvall J, Salomaa V. Endotoxemia is associated with an increased risk of incident diabetes. Diabetes Care. 2011; 34(2):392-397. PMCID: 3024355. [PubMed: 21270197]

58. Naito E, Yoshida Y, Makino K, Kounoshi Y, Kunihiro S, Takahashi R, et al. Beneficial effect of oral administration of Lactobacillus casei strain Shirota on insulin resistance in diet-induced obesity mice. Journal of applied microbiology. 2011; 110(3):650-657. [PubMed: 21281408]

59. Reigstad CS, Lunden GO, Felin J, Backhed F. Regulation of serum amyloid A3 (SAA3) in mouse colonic epithelium and adipose tissue by the intestinal microbiota. PLoS One. 2009; 4(6):e5842. PMCID: 2688757. [PubMed: 19513118]

60. Vijay-Kumar M, Aitken JD, Carvalho FA, Cullender TC, Mwangi S, Srinivasan S, et al. Metabolic syndrome and altered gut microbiota in mice lacking Toll-like receptor 5. Science. 2010; 328(5975):228-231. [PubMed: 20203013]

61. Schilder RJ, Marden JH. Metabolic syndrome in insects triggered by gut microbes. J Diabetes Sci Technol. 2007; 1(5):794-796. PMCID: 2769668. [PubMed: 19885149]

62. Cani PD, Possemiers S, Van de Wiele T, Guiot Y, Everard A, Rottier O, et al. Changes in gut microbiota control inflammation in obese mice through a mechanism involving GLP-2-driven improvement of gut permeability. Gut. 2009; 58(8):1091-1103. PMCID: 2702831. [PubMed: 19240062]

63. Lovshin J, Estall J, Yusta B, Brown TJ, Drucker DJ. Glucagon-like peptide (GLP)-2 action in the murine central nervous system is enhanced by elimination of GLP-1 receptor signaling. The Journal of biological chemistry. 2001; 276(24):21489-21499. [PubMed: 11262390]

64. Tang-Christensen M, Larsen PJ, Thulesen J, Romer J, Vrang N. The proglucagon-derived peptide, glucagon-like peptide-2, is a neurotransmitter involved in the regulation of food intake. Nature medicine. 2000; 6(7):802-807.

65. Tapiainen T, Ylitalo S, Eerola E, Uhari M. Dynamics of gut colonization and source of intestinal flora in healthy newborn infants. Apmis. 2006; 114(11):812-817. [PubMed: 17078863]

66. Favier CF, de Vos WM, Akkermans AD. Development of bacterial and bifidobacterial communities in feces of newborn babies. Anaerobe. 2003; 9(5):219-229. [PubMed: 16887708]

67. Collado MC, Isolauri E, Laitinen K, Salminen S. Distinct composition of gut microbiota during pregnancy in overweight and normal-weight women. The American journal of clinical nutrition. 2008; 88(4):894-899. [PubMed: 18842773]

68. Collado MC, Isolauri E, Laitinen K, Salminen S. Effect of mother's weight on infant's microbiota acquisition, composition, and activity during early infancy: a prospective follow-up study initiated in early pregnancy. The American journal of clinical nutrition. 2010; 92(5):1023-1030. [PubMed: 20844065]

69. Mozes S, Bujnakova D, Sefcikova Z, Kmet V. Developmental changes of gut microflora and enzyme activity in rat pups exposed to fat-rich diet. Obesity (Silver Spring). 2008; 16(12):2610 2615. [PubMed: 18927555]

70. Sefcikova Z, Bujnakova D, Racek L, Kmet V, Mozes S. Developmental changes in gut microbiota and enzyme activity predict obesity risk in rats arising from reduced nests. Physiol Res. 2011; 60(2):337-346. [PubMed: 21114359]

71. Kalliomaki M, Collado MC, Salminen S, Isolauri E. Early differences in fecal microbiota composition in children may predict overweight. The American journal of clinical nutrition. 2008; 87(3):534-538. [PubMed: 18326589] 
72. Ajslev TA, Andersen CS, Gamborg M, Sorensen TI, Jess T. Childhood overweight after establishment of the gut microbiota: the role of delivery mode, pre-pregnancy weight and early administration of antibiotics. Int J Obes (Lond). 2011; 35(4):522-529. [PubMed: 21386800]

73. Santacruz A, Marcos A, Warnberg J, Marti A, Martin-Matillas M, Campoy C, et al. Interplay between weight loss and gut microbiota composition in overweight adolescents. Obesity (Silver Spring). 2009; 17(10):1906-1915. [PubMed: 19390523]

74. Nadal I, Santacruz A, Marcos A, Warnberg J, Garagorri M, Moreno LA, et al. Shifts in clostridia, bacteroides and immunoglobulin-coating fecal bacteria associated with weight loss in obese adolescents. Int J Obes (Lond). 2009; 33(7):758-767. [PubMed: 19050675]

75. Furet JP, Kong LC, Tap J, Poitou C, Basdevant A, Bouillot JL, et al. Differential adaptation of human gut microbiota to bariatric surgery-induced weight loss: links with metabolic and low-grade inflammation markers. Diabetes. 2010; 59(12):3049-3057. PMCID: 2992765. [PubMed: 20876719]

76. Zhang H, DiBaise JK, Zuccolo A, Kudrna D, Braidotti M, Yu Y, et al. Human gut microbiota in obesity and after gastric bypass. Proceedings of the National Academy of Sciences of the United States of America. 2009; 106(7):2365-70. PMCID: 2629490. [PubMed: 19164560]

77. Aronsson L, Huang Y, Parini P, Korach-Andre M, Hakansson J, Gustafsson JA, et al. Decreased fat storage by Lactobacillus paracasei is associated with increased levels of angiopoietin-like 4 protein (ANGPTL4). PLoS One. 2010; 5(9) PMCID: 2948012.

78. Kondo S, Xiao JZ, Satoh T, Odamaki T, Takahashi S, Sugahara H, et al. Antiobesity effects of Bifidobacterium breve strain B-3 supplementation in a mouse model with high-fat diet-induced obesity. Bioscience, biotechnology, and biochemistry. 2010; 74(8):1656-1661.

79. Luoto R, Kalliomaki M, Laitinen K, Isolauri E. The impact of perinatal probiotic intervention on the development of overweight and obesity: follow-up study from birth to 10 years. Int J Obes (Lond). 2010; 34(10):1531-1537. [PubMed: 20231842]

80. Takemura N, Okubo T, Sonoyama K. Lactobacillus plantarum strain No. 14 reduces adipocyte size in mice fed high-fat diet. Experimental biology and medicine. 2010; 235(7):849-856. [PubMed: 20558839] 